EGU2020-18295

https://doi.org/10.5194/egusphere-egu2020-18295

EGU General Assembly 2020

(c) Author(s) 2020. This work is distributed under

the Creative Commons Attribution 4.0 License.

\title{
The November 112019 Le Teil, France M5 earthquake: a triggered event in nuclear country
}

\author{
Jean-Paul Ampuero ${ }^{1}$, Jérémy Billant ${ }^{1}$, Florent Brenguier ${ }^{2}$, Olivier Cavalié ${ }^{1}$, Francoise Courboulex ${ }^{1}$, \\ Anne Deschamps ${ }^{1}$, Bertrand Delouis ${ }^{1}$, Raphaël Grandin ${ }^{3}$, Romain Jolivet ${ }^{4}$, Chao Liang ${ }^{1}$, Aurélien \\ Mordret $^{2}$, and Elif Oral ${ }^{1}$ \\ ${ }^{1}$ Université Côte d'Azur, IRD, CNRS, Observatoire de la Côte d'Azur, Géoazur, Valbonne, France \\ ${ }^{2}$ Institut des Sciences de la Terre, Grenoble, France \\ ${ }^{3}$ Institut de Physique du Globe de Paris, Paris, France \\ ${ }^{4}$ Ecole Normale Supérieure, Paris, France
}

An earthquake of magnitude 5 ( $M w$ 4.9) occurred near the town of Le Teil, France on November 11 2019, causing damage locally and concern due to its proximity to nuclear facilities. Despite its moderate magnitude, this earthquake offers unique opportunities to advance basic and applied research on earthquakes in general, including our understanding of the largest and most destructive earthquakes and induced seismicity. We present here an overview of the source characteristics of this event and, based on analysis of InSAR and seismological observations and optical images, we discuss its potential relation to human activity. We also discuss the emerging unique research opportunities.

The Le Teil earthquake occurred in a low seismicity region, a moderate hazard zone that has nevertheless experienced damaging earthquakes in the past. Its hypocentral depth is particularly shallow, less than $1.5 \mathrm{~km}$. Radar images delineate the surface rupture and constrain well the coseismic slip distribution. The surface rupture corresponds to the previously mapped La Rouvière fault, an ancient normal fault reactivated as reverse-faulting by the Le Teil earthquake. Slip is predominantly confined in the top $\sim 1 \mathrm{~km}$ and extends along $\sim 4.5 \mathrm{~km}$ along-strike with two main slip asperities and stress drop of a few MPa. A large cement quarry sits on top of the deep edge of the rupture area, $\sim 1 \mathrm{~km}$ above the fault. Based on optical images we estimate the distribution of mass extracted from the nearby quarry since 1947. We then compute the induced Coulomb stresses on the fault: they are favorable for reverse faulting and reach about $150 \mathrm{kPa}$, within the range of stresses that have been previously reported to trigger earthquakes, but substantially smaller than the coseismic stress drop. Analysis of the mainshock and quarry blast signals on the nearest stations ( 8.5 to $45 \mathrm{~km}$ distance) places the mainshock epicenter within the area of influence of the quarry-induced stresses.

These analyses so far indicate that the Le Teil event is likely a triggered earthquake: its initiation was favored by the quarry-induced stresses, but the bulk of its rupture propagation was enabled by naturally pre-existing stresses. We also report on directivity analyses based on various data 
subsets, which remain to be reconciled, possibly pointing to a non-trivial rupture path.

The characteristics of the Le Teil earthquake bear on important questions: how can earthquakes nucleate at such shallow depth? what confines slip at such shallow depth? do structural features control the patchy distribution of slip? how do elongated ruptures stop? It also offers a unique opportunity to study directly, by drilling at seismogenic depth, the three key spots of an earthquake: its hypocenter, its large slip area and its arrest area. The high aspect ratio of the rupture, comparable to that of the largest earthquakes, opens a window into the physics of very large earthquakes. Continued research would also address implications for seismic hazard in lowseismicity areas, including the safety of nearby nuclear power plants, especially by monitoring the unbroken sections of the fault system. 